\title{
A study to correlate association between vitamin $D$ with fibroid and its supplementation in the progression of the disease
}

\author{
Somila Xess*, Jaiprakash Sahu
}

Department of Obstetrics and Gynecology, GMC Ambikapur, Chhattisgarh, India

Received: 17 January 2020

Revised: 21 February 2020

Accepted: 28 February 2020

\author{
*Correspondence: \\ Dr. Somila Xess, \\ E-mail: somilaxess05@gmail.com
}

Copyright: (C) the author(s), publisher and licensee Medip Academy. This is an open-access article distributed under the terms of the Creative Commons Attribution Non-Commercial License, which permits unrestricted non-commercial use, distribution, and reproduction in any medium, provided the original work is properly cited.

\begin{abstract}
Background: Uterine fibroids, or leiomyomas are the most common benign tumors of the female reproductive tract, affecting up to $60 \%$ of Indian women with only $25 \%$ of women who are symptomatic. Symptoms do not always correlate with the size, number, or location of the fibroids. Recent studies suggest that hypovitaminosis D is associated with an increased risk of uterine fibroids.

Methods: Total 110 women diagnosed with fibroid in USG were included in the study. Inclusion and exclusion criteria were applied and size of the fibroid noted. 60 women were included in the study group who took Vitamin D supplementation and 50 women in the control group who didn't perform the study properly.

Results: The growth pattern of fibroids with study group under supplementation with 25-OH-D3 seems to be stable, with no increases or decreases in size or number of identified lesions. Instead, women in control group, who did not perform appropriate vitamin D supplementation seem to have a slight but significant increase in size of the lesions. Conclusions: It was seen that hypovitaminosis D was associated with fibroid and thus supplementation with Vitamin $\mathrm{D}$ helped in the shrinkage of fibroid or slower the progression of the disease.
\end{abstract}

Keywords: Fibroid, Hypovitaminosis, Vitamin D

\section{INTRODUCTION}

Uterine leiomyomas (fibroids) are the most common gynecologic tumors in females.

They are benign clonal tumor that arise from the smooth muscle cells of the uterus and contain excessive extracellular matrix (ECM). Leiomyoma are well known estrogen (E)-dependent tumors in the uterus of premenopausal females. ${ }^{1-4}$ Leiomyomas clinically affect more than $25 \%$ of reproductive age females and cause significant morbidity. ${ }^{5,6}$ Although the majority of females with uterine leiomyoma are asymptomatic, symptomatic leiomyomas can cause abnormal uterine bleeding, pelvic pressure and pain, and urinary incontinence or retention, and are associated with infertility and recurrent abortion. $^{7-10}$

Conventional medical treatments include oral contraceptives, gonadotropin-releasing hormone $(\mathrm{GnRH})$ analogs, mifepristone. Ulipristal acetate (UPA), a selective progesterone receptor modulator, has been introduced as a new medical strategy in the treatment of uterine fibroids with promising results. ${ }^{11}$ These medical treatments are commonly used for women with symptomatic fibroid. Surgical management includes myomectomy and hysterectomy. Recent, studies suggest that hypovitaminosis D is associated with an increased risk of uterine fibroids. ${ }^{12-15}$ Moreover, vitamin D inhibits the growth and promotes the apoptosis of fibroid cells in 
"in vitro" studies, and it seems to reduce the fibroid size in "in vivo" animal models. ${ }^{16-21}$ According to these findings, vitamin D supplementation might be an effective, safe, and low cost therapy in the primary prevention and treatment of uterine fibroids.

Objectives of this study was to study vitamin D status in women with fibroid. To evaluate fibroid characteristics after vitamin D supplementation.

\section{METHODS}

This is a cohort study carried out at Government medical college Ambikapur from December 2018 to November 2019. Total 110 women diagnosed with fibroid in pelvic USG were included in the study and inclusion and exclusion criteria was applied. All the ultrasound examinations were performed with a high-resolution system with the use of a 3.5 to $5.5 \mathrm{mHz}$ probe, by the same sonologist.

\section{Inclusion criteria}

- At least one uterine fibroid

- Mean diameter $\geq 10 \mathrm{~mm}$.

\section{Exclusion criteria}

- Those with ongoing vitamin D supplementation for other clinical reasons (e.g., osteoporosis)

- Previous diagnosis of hypovitaminosis D

- Size more than $5 \mathrm{~cm}$

- More than 4 fibroids

- Those with severe symptoms requiring urgent intervention.

The characteristics of each patient's fibroids (number, size, and location) were accurately reported. In particular, 3 perpendicular diameters $(\mathrm{d} 1, \mathrm{~d} 2$, and $\mathrm{d} 3$ in $\mathrm{mm})$ were collected for each fibroid and, according to previous studies, the volume of each fibroid (in $\mathrm{cm}^{3}$ ) was calculated with the ellipsoid formula: $4 / 3 \times \Pi \times(\mathrm{d} 1 \times \mathrm{d} 2$ $\times \mathrm{d} 3) / 8$. For each patient, the total volume of fibroids (defined as the sum of the volumes of all the fibroids detected) was also calculated.
The background and clinical characteristics of each patient were recorded: age, body mass index (BMI), tobacco use, and comorbidities were considered. Similarly, the obstetric and gynecological history and the lifestyle habits of each woman (with specific interest in dietary habits and sun exposure) were also recorded. Fibroids-related symptoms were accurately investigated, and, in particular, dysmenorrhea, pelvic pain, dyspareunia, and menstrual disorders were reported.

These women, the 25-hydroxy-cholecalciferol (25-OHD3), levels were determined (the same day of the ultrasound examination). While the definition of vitamin D deficiency tends to vary, study decided to utilize the 2011 endocrine society definition of vitamin D deficiency $(<20 \mathrm{ng} / \mathrm{mL})$, and vitamin D insufficiency (21$29 \mathrm{ng} / \mathrm{mL}){ }^{22}$ Those with either deficiency or insufficiency $\mathrm{D}$ were offered standard supplementation therapy with $60,000 \mathrm{IU}$ of cholecalciferol (oral solution) once per week for 12 weeks, followed by maintenance therapy of 2000 IU weekly for a year. Follow up done telephonically at 3 and 6 months and OPD visit at one year by USG and measurement of 25-hydroxy-cholecalciferol (25-OH-D3) levels.

The "progression to extensive disease" was defined by the increase in size of uterine fibroids (with the development of one or more fibroids $>50 \mathrm{~mm}$ ) or by a significant worsening of fibroids related symptoms in the 12 months after the initial diagnosis. These women were offered a medical therapy or a surgical procedure (hysterectomy or myomectomy). The women with a "progression to extensive disease" were excluded from the final analysis, as well as the women who reported a pregnancy in the 12 months after the initial diagnosis.

\section{RESULTS}

Total 300 women underwent gynaecology ultrasound of which 110 fulfilled our inclusion criteria and were included in the study. Written and informed consent was taken and sociodemographic factors noted along with supplementation of Vitamin D. The mean \pm SD 25-OH-D3 serum level was $25.7 \pm 10.7 \mathrm{ng} / \mathrm{mL}$.

Table 1: Vitamin D, and fibroids characteristics in the study group and the control group at inclusion and after 1 year.

\begin{tabular}{|llll|}
\hline Characteristics & Inclusion & After 1 year & p value \\
\hline Study group $\mathrm{n}=60$ & & & $<0.001$ \\
\hline Vitamin D levels & $19.9 \pm 1.0$ & $30.7 \pm 10.5$ & 0.63 \\
\hline Diameter $(\mathrm{mm})$ & $20(17.3-38.8)$ & $20(15.8-35.8)$ & 0.63 \\
\hline Volume, $\mathrm{cm}^{3}$ & $8.2(2.7-30.5)$ & $8.2(2.1-28.5)$ & 0.38 \\
\hline Control group $\mathrm{n}=50$ & & & $<0.001$ \\
\hline Vitamin D levels & $21.4 \pm 8.4$ & $23.1 \pm 7.6$ & $<0.001$ \\
\hline Diameter $(\mathrm{mm})$ & $25(20-34.5)$ & $28(22-35)$ & $11.4(5.5-22.3)$ \\
\hline Volume, $\mathrm{cm}^{3}$ & $8.2(4.2-21.4)$ & & \\
\hline
\end{tabular}


Table 2: Background and clinical characteristics among responders and non-responders.

\begin{tabular}{|llll|}
\hline Characteristics & Responders $\mathbf{n}=\mathbf{4 2}$ & Non responders $\mathbf{n}=\mathbf{8}$ & p value \\
\hline Age, year & $45 \pm 5.0$ & $45 \pm 3.7$ & 1.000 \\
\hline BMI, $\mathrm{kg} / \mathrm{m}^{2}$ & $27.3 \pm 5.7$ & $27.7 \pm 5.0$ & 0.81 \\
\hline Muslims & $18(42.8 \%)$ & $3(37.5 \%)$ & 0.90 \\
\hline Menarche & $12(11-12.75 \%)$ & $12(11.25-13 \%)$ & 0.78 \\
\hline Total number of pregnancies & $1-2$ & $1-4$ & \\
\hline PCOS & 0 & 0 & 0.45 \\
\hline Past OC use & $6(14.2 \%)$ & $2(25 \%)$ & 0.62 \\
\hline Spontaneous miscarriage & $3(7.14 \%)$ & $1(12.5 \%)$ & \\
\hline
\end{tabular}

Table 3: Fibroid characteristics in responders and non-responders.

\begin{tabular}{|llll|}
\hline Characteristics & Responders $\mathbf{n}=\mathbf{4 2}$ & Non responders $\mathbf{n}=\mathbf{8}$ & $\mathbf{p}$ value \\
\hline Number of fibroids & $1(1-2 \%)$ & $1(1-2 \%)$ & 0.75 \\
\hline Initial diameter, $\mathrm{mm}$ & $19(17.3-38.8)$ & $20(15.5-38)$ & 0.93 \\
\hline Initial volume, $\mathrm{cm}^{3}$ & $9.2(2.1-32.8)$ & $9.2(2.1-30)$ & 0.93 \\
\hline Final diameter, $\mathrm{mm}$ & $20(18-35)$ & $22(14.3-33.8)$ & 0.80 \\
\hline Final volume, $\mathrm{cm}^{3}$ & $8.6(3.3-57.1)$ & $8.9(1.5-20.2)$ & 0.80 \\
\hline
\end{tabular}

Among women with hypovitaminosis D, 60 patients performed the therapy adequately and constituted the "study group". In the 12 months after the initial diagnosis, 3 women of the study group got pregnant $(5.0 \%)$ and 7 women $(11.6 \%)$ underwent traditional medical or surgical therapy because of the "progression to extensive disease" ( 2 women underwent surgical procedures and 5 underwent medical therapy). The remaining 50 women (16 who refused the supplementation therapy and 34 who did not perform it adequately) constituted the "control group."

In the 12 months after the initial diagnosis, 4 women of the "control group" got pregnant $(8 \%)$ and 17 women (34\%) underwent medical or surgical therapy because of the "progression to extensive disease" ( 7 women underwent surgical procedures and 10 underwent medical therapy). In the "study group," no difference in the baseline vitamin D levels emerged between patients with or without "progression to extensive disease" $(21.1 \pm 5.1$ versus $19.9 \pm 6.9, \mathrm{p}=0.44)$. Even in the "control group," no difference in the baseline vitamin D levels emerged between patients with or without "progression to extensive disease" (20.6 \pm 5.5 versus $21.4 \pm 8.4, \mathrm{p}=0.71)$. The rate of women with "progression to extensive disease" was significantly lower in the "study group" compared with controls $(11.6 \%$ versus $34 \%)$. In relation to the achievement of normal 25-OH-D3 levels, study identified 2 subgroups of patients: "responders" and "non-responders". Among the 50 women left of the study group, 42 were responders and 8 were non-responders. Responder's were those who achieved normalization of vitamin D levels after supplementation and nonresponders who didn't.

Considering the 60 women of the "study group", the mean \pm SD baseline 25-OHD3 serum level was $19.9 \pm 1.0$ $\mathrm{ng} / \mathrm{mL}$. At the call back visit (performed 12 months after the starting of appropriate vitamin D supplementation therapy), the mean 25-OH-D3 level in these women was $30.7 \pm 10.5 \mathrm{ng} / \mathrm{mL}$; thus, the difference was statistically significant $(19.9 \pm 1.0$ versus $30.7 \pm 10.5 \mathrm{ng} / \mathrm{mL} ; \mathrm{p}<0.001)$ (Table 1). The background and clinical characteristics were also studied which showed not statistically significance. Muslims had vitamin D deficiency may be due to lesser exposure to sun (Table 2).

In the women of the "control group" for which the call back visit was performed, the mean \pm SD baseline $25-\mathrm{OH}$ D3 serum level was $21.4 \pm 8.4 \mathrm{ng} / \mathrm{mL}$. At the call back visit (performed 12 months after the initial diagnosis), the mean 25-OH-D3 serum level was $23.1 \pm 7.6 \mathrm{ng} / \mathrm{mL}$; thus, no significant difference was reported $(21.4 \pm 8.4$ versus $23.1 \pm 7.6 \mathrm{ng} / \mathrm{mL} ; \mathrm{p}=0.38$ ).

Among the "study group" there were total 64 fibroids and 35 in the women of the "control group." The number, topographic site, and location of all lesions remained the same between the initial and the final ultrasounds.

One year after the initial diagnosis, considering the 50 women of the "study group" for which the call back visit was performed, 42 patients $(84 \%)$ reached normal levels of 25-OH-D3 ("responders"), while 8 (16\%) did not reach a normal level("non-responders"). The "responders" had a baseline 25-OH-D3 serum level of $20.3 \pm 7.4 \mathrm{ng} / \mathrm{mL}$ and then $40.1 \pm 9.1 \mathrm{ng} / \mathrm{mL}$ after 1 year of therapy $(\mathrm{p}<0.001)$.

The "non-responders" had a starting 25-OH-D3 level of $19.6 \pm 6.7 \mathrm{ng} / \mathrm{mL}$ and a final level of $23.9 \pm 4.7 \mathrm{ng} / \mathrm{mL}$ $(\mathrm{p}=0.01)$. No significant differences in background or clinical characteristics between the "responders" and "non-responders" (Table 3). 
Among the "responders," 24 patients (57.1\%) presented a single fibroid, while multiple fibroids were detected in 18 patients (42.8.8\%). Among the "non-responders," 3 women $(37.5 \%)$ presented a single fibroid, while multiple fibroids were detected in 5 patients $(62.5 \%)$. The characteristics of uterine fibroids in the 2 groups were similar.

\section{DISCUSSION}

Hypovitaminosis D has recently been associated with a higher prevalence of uterine fibroids, and some authors reported that vitamin D serum levels are inversely correlated with the severity of uterine fibroids. ${ }^{23}$

Recent "in vitro" studies have explored the potential role of vitamin D in the development of uterine fibroids. It has been demonstrated that vitamin $\mathrm{D}$ inhibits the growth of fibroid cells through the down-regulation of proliferating cell nuclear antigen (PCNA), cyclin-dependent kinase 1, and B-cell lymphoma 2 (and suppresses the catechol-Omethyltransferase expression and its activity). ${ }^{17}$ In addition, vitamin $\mathrm{D}$ seems to reduce the transforming growth factor beta-3 effects on the process of fibrosis in human fibroid cells and to limit the aberrant expression of major extracellular matrix-associated proteins. ${ }^{18,20}$

Study results confirm the correlation between hypovitaminosis $\mathrm{D}$ and uterine fibroids since we found that lower levels of vitamin D are related to a more severe uterine disease, in terms of volume of the largest fibroid and volume of total fibroids as well as the diameter. Moreover, in 2012, Halder et al, found that treatment with 1,25- OH-D3 significantly reduces fibroid tumor size in Eker rats by suppressing cell growth and proliferation-related genes, antiapoptotic genes, and estrogen and progesterone receptors. ${ }^{19}$

Study preliminary data suggest that 25-OH-D3 is effective in restoring normal levels of vitamin $\mathrm{D}$ in women with uterine fibroids. After 1 year of therapy, the mean level of 25-OHD3 in the study group was significantly higher compared with the baseline level $(30.7 \pm 10.5$ versus $19.9 \pm 7.0 \mathrm{ng} / \mathrm{mL}, \mathrm{p}<0.001)$.

Out of 60 women studied, only 10 (16.6) developed progression to extensive disease which indicates that vitamin D slower the progression of the disease. On the other hand, in the control group $42 \%$ required urgent measures. Also, the study highlights that $8(16 \%)$ of women didn't respond to vitamin D supplementation which may be due to genetic factors, BMI, and baseline levels.

The effect of vitamin D supplementation was also examined by comparing the sonographic features of uterine fibroids at inclusion and 12 months after the initial diagnosis, both in patients who had properly performed the therapy (study group) and in those who did not adequately perform the therapy (control group). No significant differences were found in diameter or in volume of the identified fibroids in the study group, while a slight but significant increase in diameter and volume was noted in the control group. Thus, the growth pattern of fibroids with study group under supplementation with 25-OH-D3 seems to be stable, with no increases or decreases in size or number of identified lesions. Instead, women in control group, who did not perform appropriate vitamin D supplementation seem to have a slight but significant increase in size of the lesions and a higher need for subsequent medical or surgical therapy.

This study has some potential limitations due to small sample size. Obviously, in order to investigate the potential role of vitamin D supplementation therapy in women with uterine fibroids, appropriate well-designed randomized controlled trials (RCTs) should be performed.

\section{CONCLUSION}

Thus, women with fibroids were noted with deficiency of vitamin $\mathrm{D}$ and mere supplementation can slower the progression of small burden disease.

Funding: No funding sources

Conflict of interest: None declared

Ethical approval: Not required

\section{REFERENCES}

1. Cook JD, Walker CL. Treatment strategies for uterine leiomyoma: the role of hormonal modulation. Semin Reprod Med. 2004;22:105-11.

2. Eltoukhi HM, Modi MN, Weston M, Armstrong AY, Stewart EA. The health disparities of uterine fibroid tumors for African American women: a public health issue. Am J Obstet Gynecol. 2014;210:194-9.

3. Metwally M, Farquhar CM, Li TC. Is another metaanalysis on the effects of intramural fibroids on reproductive outcomes needed? Reprod Biomed. 2011;23:2-14.

4. Eldar-Geva T, Healy DL. Other medical management of uterine fibroids. Baillieres Clin Obstet Gynaecol. 1998;12:269-88.

5. Guo XC, Segars JH. The impact and management of fibroids for fertility: an evidence-based approach. Obstet Gynecol Clin North Am. 2012;39:521-33.

6. Khan AT, Shehmar M, Gupta JK. Uterine fibroids: current perspectives. Int $\mathrm{J}$ Womens Health. 2014;6:95-114.

7. Farhi J, Ashkenazi J, Feldberg D, Dicker D, Orvieto R, Ben Rafael Z. Effect of uterine leiomyomata on the results of in-vitro fertilization treatment. Hum Reprod. 1995;10:2576-8.

8. Eldar-Geva T, Meagher S, Healy DL, MacLachlan $\mathrm{V}$, Breheny S, Wood C. Effect of intramural, subserosal, and submucosal uterine fibroids on the outcome of assisted reproductive technology treatment. Fertil Steril. 1998;70:687-91.

9. Hart R, Khalaf Y, Yeong CT, Seed P, Taylor A, Braude P. A prospective controlled study of the effect of 
intramural uterine fibroids on the outcome of assisted conception. Hum Reprod. 2001;16:2411-7.

10. Surrey ES, Lietz AK, Schoolcraft WB. Impact of intramural leiomyomata in patients with a normal endometrial cavity on in vitro fertilization-embryo transfer cycle outcome. Fertil Steril. 2001;75:405-10.

11. Trefoux Bourdet A, Luton D, Koskas M. Clinical utility of ulipristal acetate for the treatment of uterine fibroids: current evidence. Int $\mathrm{J}$ Womens Health. 2015;7:321-30.

12. Al-Hendy A, Badr M. Can vitamin D reduce the risk of uterine fibroids? Womens Health (Lond). 2014;10:353-8.

13. Brakta S, Diamond JS, Al-Hendy A. Role of vitamin $\mathrm{D}$ in uterine fibroid biology. Fertil Steril. 2015;104:698-706.

14. Wu JL, Segars JH. Is vitamin D the answer for prevention of uterine fibroids? Fertil Steril. 2015;104:559-60.

15. Paffoni A, Somigliana E, Vigano' P. Vitamin D status in women with uterine leiomyomas. J Clin Endocrinol Metab. 2013;98:E1374-8.

16. Baird DD, Hill MC, Schectman JM. Vitamin D and the risk of uterine fibroids. Epidemiol. 2013;24:447-53.

17. Sharan C, Halder SK, Thota C. Vitamin D inhibits proliferation of human uterine leiomyoma cells via catechol-O-methyltransferase. Fertil Steril. 2011;95:247-53.

18. Halder SK, Goodwin JS, Al-Hendy A. 1,25Dihydroxyvitamin D3 reduces TGF-beta3-induced fibrosis-related gene expression in human uterine leiomyoma cells. J Clin Endocrinol Metab. 2011;96:E754-62.

19. Halder SK, Sharan C, Al-Hendy A. 1,25Dihydroxyvitamin D3 treatment shrinks uterine leiomyoma tumors in the Eker rat model. Biol Reprod. 2012;86:116.

20. Halder SK, Osteen KG, Al-Hendy A. Vitamin D3 inhibits expression and activities of matrix metalloproteinase- 2 and -9 in human uterine fibroid cells. Hum Reprod. 2013;28:2407-16.

21. Halder SK, Osteen KG, Al-Hendy A. 1,25Dihydroxyvitamin D3 reduces extracellular matrix associated protein expression in human uterine fibroid cells. Biol Reprod. 2013;89:150.

22. Holick MF, Binkley NC, Bischoff-Ferrari HA, Gordon CM, Hanley DA, et al. Evaluation, treatment, and prevention of vitamin D deficiency: an Endocrine Society clinical practice guideline. J Clin Endocrinol Metab.2011;96:1911-30.

23. Sabry M, Halder SK, Allah AS. Serum vitamin D3 level inversely correlates with uterine fibroid volume in different ethnic groups: a cross-sectional observational study. Int $\mathrm{J}$ Womens Health. 2013;5:93-100.

Cite this article as: Xess $\mathrm{S}$, Sahu J. A study to correlate association between vitamin $\mathrm{D}$ with fibroid and its supplementation in the progression of the disease. Int J Reprod Contracept Obstet Gynecol 2020;9:1477-81. 